\title{
1 The effect of the scalp on the effectiveness of bicycle helmets' anti-rotational
}

\section{2 acceleration technologies}

3 Dimitris Zouzias, ${ }^{\mathrm{a}, \mathrm{b}, *}$, Guido De Bruyne ${ }^{\mathrm{b}, \mathrm{e}}$, Aisling Ni Annaidh ${ }^{\mathrm{c}, \mathrm{d}^{*}}$, Antonia Trotta ${ }^{\mathrm{c}}, \mathrm{Jan}_{\text {Ivens }}^{\mathrm{a}}{ }^{\mathrm{a}}$

4 aDepartment of Materials Engineering, KU Leuven Campus De Nayer Sint-Katelijne Waver, Belgium; ${ }^{\mathrm{b}}$ LazerSport,

5 Lamorierestraat 33, Antwerp, Belgium; ' School of Mechanical \& Materials Engineering, University College Dublin, Belfield,

6 Dublin 4, Ireland; dUCD Charles Institute of Dermatology, School of Medicine and Medical Science, University College Dublin,

7 Belfield, Dublin 4, Ireland; eProduct Development, Faculty of Design Sciences, University of Antwerp, Antwerp, Belgium;

8 *Corresponding author Frederik de Merodestraat 8-16, 2600, Belgium email:dimitrios.zouzias@kuleuven.be (D. Zouzias);

$9 *$ Corresponding author University College Dublin, Belfield, Dublin 4, Ireland email:antonia.trotta@ucdconnect.ie (A. Trotta) 


\title{
1 The effect of the scalp on the effectiveness of bicycle helmets' anti-rotational
}

\section{2 acceleration technologies}

${ }^{\mathrm{a} D}$ Department of Materials Engineering, KU Leuven Campus De Nayer Sint-Katelijne Waver, Belgium; ${ }^{\text {LazerSport, }}$ Lamorierestraat 33, Antwerp, Belgium; ${ }^{c}$ School of Mechanical \& Materials Engineering, University College Dublin, Belfield, Dublin 4, Ireland; 'UCD Charles Institute of Dermatology, School of Medicine and Medical Science, University College Dublin, Belfield, Dublin 4, Ireland; 'Product Development, Faculty of Design Sciences, University of Antwerp, Antwerp, Belgium; *Corresponding author Frederik de Merodestraat 8-16, 2600, Belgium email:dimitrios.zouzias@ kuleuven.be (D. Zouzias); *Corresponding author University College Dublin, Belfield, Dublin 4, Ireland email:antonia.trotta@ ucdconnect.ie (A. Trotta)

\begin{abstract}
Objective: Medical data has lead to the common understanding that bicycle helmets need to be improved to better protect against brain injuries resulting from rotational acceleration. Although many different technologies exist for reducing rotational acceleration during impacts, the lack of an official testing standard means that their evaluation is based on customised set-ups that may differ and not represent real accident conditions. Previously, the authors have shown that scalp tissue plays an important role during helmet testing by absorbing energy and creating a low friction interface between head and helmet, thus reducing rotational accelerations and velocities. However, no published study has yet examined the effectiveness of anti-rotational helmet technologies in the presence of a biofidelic scalp layer. The objective of this study is to address this gap.
\end{abstract}

Methods: Three different commercially available helmet models, each one equipped with a different technology, were tested in the presence of scalp tissue, in two different scenarios; with and without the technology present. The effectiveness of each of these technologies is already documented in other studies, but only in the absence of a biofidelic scalp layer. Tests were carried out using HIII headform with porcine scalp attached to the outmost layer. Motion tracking was used to compare the impact kinematics of each helmet model in both scenarios.

Results: Results showed that when a biofidelic scalp layer is present, there is no statistical difference between helmet models with and without the anti-rotational technology in terms of rotational acceleration, velocity, relative rotation, impact duration and injury risk.

Conclusions: Results suggest that the presence of the scalp can obscure the functionality of anti-rotational acceleration technologies. This could indicate that the effectiveness of technologies tested in previous studies, which have not tested anti-rotational acceleration technologies in the presence of a realistic scalp layer, may exaggerate the contribution of such technologies if compared with a more biofidelic set-up. The study supports the fact that headforms should be better designed by incorporating artificial skin layers that can better imitate scalp's behaviour and, in addition, provides insights for the design of technologies against rotational acceleration.

KEYWORDS: head injuries, scalp, bicycle helmet, standard tests, friction coefficient, rotational acceleration

\section{Introduction}

Rotational acceleration of the brain during accidents, is considered to be one of the factors leading to brain injuries (Sahoo et al. 2016). The majority of cycling accidents involve oblique impacts at angles of 30-60 
et al. 2014) leading to such loading conditions. In order to enhance helmet safety, several concepts designed to mitigate against rotational acceleration have been developed and tested. A number of researchers focus on the sliding properties between head-helmet (Approach_1), showing that lower friction decreases rotational acceleration and therefore injury risk (McIntosh et al 1998). This approach has led to solutions like LAZER's Superskin and Multi-Directional Impact Protection System (MIPS). A different approach (Approach_2) is based on deformable materials that reduce the shear stiffness of the helmet such as KALI's Low Density Layer (LDL), POC's Spin and WAVECEL (Bliven et al 2019).

Certification of bicycle helmets involves only linear impact tests. Novel methods have been proposed for oblique impact testing, which incorporate falls onto sliding surfaces (McIntosh et al 1998), oblique anvils, (Bland et al 2018; Klug et al 2015) or pendulums (Rowson et al 2015). Commercially available rating tests such as the STAR rating method by Bland et al. 2019 and the method by Deck et al. 2019 coupled with the SUFEHM toolbox, incorporate drops on oblique anvils. Among the headforms used for those experiments, Hybrid III (HIII) with or without a neckform was chosen as it most accurately matches the moment of inertia (MOI) of the human head in the y-axis which passes through the ears (Connor et al. 2018). However the vinyl layer covering HIII has over twice the friction of the human head (Trotta et al 2018b) which influences impact kinematics (Ebrahimi et al. 2015; Kendall et al. 2012). HIII was developed by General Motors to simulate car accidents. The main goal was the development of a headform, durable enough to sustain multiple impacts, without intending to include a biofidelic scalp layer. To study its effect on impact mechanics Ebrahimi et al. (2015) performed oblique impact tests on a magnesium headform with a silicone layer to simulate human scalp. For lateral impacts ( $30^{\circ}$ anvil), they reported $89 \%$ increase in rotational acceleration concluding that the material covering the headform, and its surface friction, can affect rotational acceleration. Kendall et al. (2012) reached similar conclusions by comparing the response of HIII covered with vinyl and Hodgson-WSU headform covered with urethane on direct impacts. While Bland et al 2018 conducted oblique impacts $(6 \mathrm{~m} / \mathrm{s})$ comparing helmeted HIII and NOSCAE headforms with and without neckform. Rotational velocity and acceleration were $22 \%$ and $31 \%$ greater for HIII, partially attributed to the different MOI and the higher CoF of HIII surface. The detached headform produced 17-35\% greater acceleration. Human scalp is loosely attached to the skull by the connective tissue anteriorly with the orbicularis oculi muscles, laterally to the frontal process of the zygoma, and in the back of the head to the superior nuchal line (Tolhurst et al 1991). The limited and loose connection between scalp-skull, allows the scalp to slide with small resistance $(\mathrm{CoF}=0.06)$ over the skull (Trotta et al 2018b). Tensile experiments by Pramudita. et al (2014) showed that porcine skin is a good surrogate for human scalp. It is commonly used in clinical studies e.g. skin graft (Ge et al 2011) and surgery simulation (Bowling et al 2006). While there is a reported difference in Elasticity Modulus between human and porcine scalp of 15 to $40 \mathrm{MPa}$ depending on the strain-rate (Trotta et al. 2019), the sliding properties and strain at failure are comparable, which is of greater relevance in the current study. Trotta et al (2018a) performed linear and oblique impacts with HIII and EN960 headforms. The performance of the headforms was compared to that of a modified version with porcine scalp attached, during helmeted and un-helmeted impacts. In all helmeted cases the same helmet model was used. Depending on the impact location, rotational acceleration in the presence of the scalp showed a reduction of up to $70 \%$ for un-helmeted and $54 \%$ for helmeted cases, supporting the need for a material capable of sliding over the headform. Despite the potential protective function of the scalp, little importance has been given to it in testing protocols. 
The contribution of several anti-rotational acceleration technologies to helmet safety has already been investigated by researchers. Stigson et al. (2017) tested 19 helmets, some incorporating MIPS and POC technologies using HIII. Helmets with integrated technologies outperformed ordinary helmets. Likewise Zouzias et al (2017) studied the kinematics of HIII during impact by testing three different helmet models with and without MIPS technology. It was shown that the presence of the technology can reduce rotational acceleration by increasing sliding of the head with respect to the helmet's liner.

Several authors have used nylon stockings in order to reduce surface friction of HIII. Bottlang et. al. (2020) used HIII with an attached neckform, covered with nylon stockings, to test MIPS, POC SPIN, ODS and LDL technologies. They observed a reduction in rotational acceleration of 22\% and 37\% for MIPS and POC respectively and an increase of $61 \%$ for LDL, attributed to the difference in density of the tested helmet compared to the reference and not to the technology itself. No difference was observed for ODS. Bliven et al. (2019) also used HIII headform/neckform assembly, covered with nylon stockings to test MIPS and WAVECELL showing a reduction in rotational acceleration by $22 \%$ and $73 \%$ respectively. While this approach successfully reduces the CoF, the low friction covering does not replicate the complex structure or energy absorbing properties of the in-vivo scalp.

Despite studies assessing the performance of technologies mitigating rotational acceleration, to the authors' knowledge, there are no previous studies which assess their functionality in the presence of biofidelic scalp tissue. The aim of this study is to evaluate the effectiveness of such technologies in presence of scalp tissue. This can provide improved insights for the development of new testing standards, headforms and helmet design.

\section{Methods}

Experiments were conducted at room temperature, using a free fall monorail drop tower with measuring frequency of $50 \mathrm{kHz}$. Frontal oblique impact tests were conducted, cantered on the sagittal midline of the helmet with the anvil's surface aligned parallel to the headform's transverse axis (Bliven et al. 2019). A $45^{\circ}$ stainless-steel anvil (8.2 kg) covered with sandpaper (grid 40) and HIII (4.54 kg) equipped with 9 accelerometers were used. The velocity of the impact was $6 \mathrm{~m} / \mathrm{s}$ as a reasonable compromise of the recommended velocities for a $45^{\circ}$ anvil (Klug et al 2015; Stigson et al. 2017). Tests were recorded with a high-speed camera with a frame-rate of $3600 \mathrm{fps}$ and resolution of $864 \times 864$ pixels.

Fresh porcine scalp (without hair), containing the skin and the subcutaneous tissue, was obtained from a local abattoir. The rubber layer that is covering HIII, is designed to protect the instrumentation and the frame underneath, reassuring its functionality(Kendall et al. 2012). To avoid damage, the scalp tissue was attached with superglue to the rubber layer of HIII at the relevant anatomical areas of connection mentioned in the introduction. The entire front-half of the headform was covered with scalp as illustrated in Figure 1. Only the rear of the helmet-where the fitting system is installed-remained uncovered. In this region, direct contact between headform and helmet is, by design, avoided with a small gap between head-helmet so that the available helmet sizes can fit all head sizes. In all models tested, the technologies are kept outside this area. As a result, the functionality of the technologies in this region is not pronounced, allowing the presence of the scalp there to be omitted. Furthermore, since all impacts are frontal and very localised, coverage of the front half was considered sufficient. The CoF between scalp-skull and between scalp-liner has been previously measured to be 0.06 and 0.29 respectively (Trotta et al 2018b). To 
reduce scalp-HIII rubber friction, the rubber layer was covered with duct tape before placing the scalp on top (Trotta et al 2018a). In all cases the tissue layer followed the shape of the headform. Using callipers, the thickness of the porcine scalp was measured to be between 3-7mm, values comparable with the human scalp (3-8mm) (Seery et al 2002). This corresponds to a $3.5 \%$ increase in the distance between the headform's center of gravity (CoG) and the mid-surface of the scalp layer on the forehead where the impact takes place (distance between headform's CoG and forehead=97.8mm).

[Position of Figure 1]

Three technologies were chosen for assessment: KALI's LDL, POC's Spin (Model_1 and 2,Approach_2) and MIPS (Model_3, Approach_1) (Appendix Figure A1) so that both Approaches presented in the introduction are represented. Model_1 and Model_2 are based on the low shearing resistance of the materials between head and helmet's liner (Approach_2). The deforming material of these two technologies is placed on the internal surface of the helmet in between head and helmet, in contrast with other approaches (Koroyd, Wavecel) where it is integrated within the helmet. Model_3 uses a low friction layer between the headform and helmet's liner (Approach_1). The layer is connected to the helmet through elastic strings. Models_2 and 3 are available for purchase both with and without the technology. Model_1, however comes only with the LDL technology. In order to provide control samples, the LDL pads were manually removed from the helmets. All pads are glued to the helmet's liner, so they can be easily removed without damaging the liner. A new helmet and scalp sample was used for each experiment. The tissue and attachment points were inspected after each impact. In all cases the connection between scalp and headform was preserved.

The maximum shearing deformation of the pads for Model_1 and 2 was measured with a calliper to be 1-2 and $2 \mathrm{~mm}$ respectively. Similarly, the elongation of the strings for Model_3 was $10-15 \mathrm{~mm}$. Since deformations were measured during quasi-static loading, some deviation might be expected during impact. The extent to which each of the interfaces contributes to the relative motion between head and helmet will define the difference in performance between the two versions of helmets. All technologies should remain active long enough during impact for their functionality to significantly influence the outcome.

To compare the kinematics of the helmets with and without the technologies, motion tracking was used_. The relative head-helmet rotation was measured by monitoring the trajectories of 4 tracking points, two on the surface of the headform and two either marked on the helmet or by using design features. Each trajectory was defined using Tracker (Brown 2011). The software allows the definition of a global axes system for calculating the coordinates of each tracking point.

From the coordinates of each point, the head's and helmet's angle of rotation with respect to the horizontal plane and thus their relative rotation was calculated (Zouzias et al 2017) (Appendix Figure A2). Since sliding contributes to the reduction of rotational acceleration, differences in relative rotation between helmets with and without a technology, were considered as indicators of the technology's functionality. Three trials were performed for both enhanced and regular versions. Impact duration, angular velocity, linear and rotational acceleration were measured and the Brain Injury Criterion (BRIC) was calculated for each impact (Bliven et al 2019; Bottlang et. al. $\underline{2020)}$. 
Results were analysed using Matlab R2018a. Data were filtered using CFC1000 filter. Multi-way ANOVA test was used to evaluate the effect of the technologies on the kinematics of impact. A p-value $<0.05$ was chosen to identify statistical significance.

\section{Results}

The rotational acceleration (average \pm standard deviation) undergone by the helmeted HIII with and without the technology is shown in Figure 2 and Figure A3.

\section{[Position of Figure 2]}

Peak rotational and linear acceleration, angular velocity, impact time and BRIC (average value \pm standard deviation) are presented

in

Figure

3

and
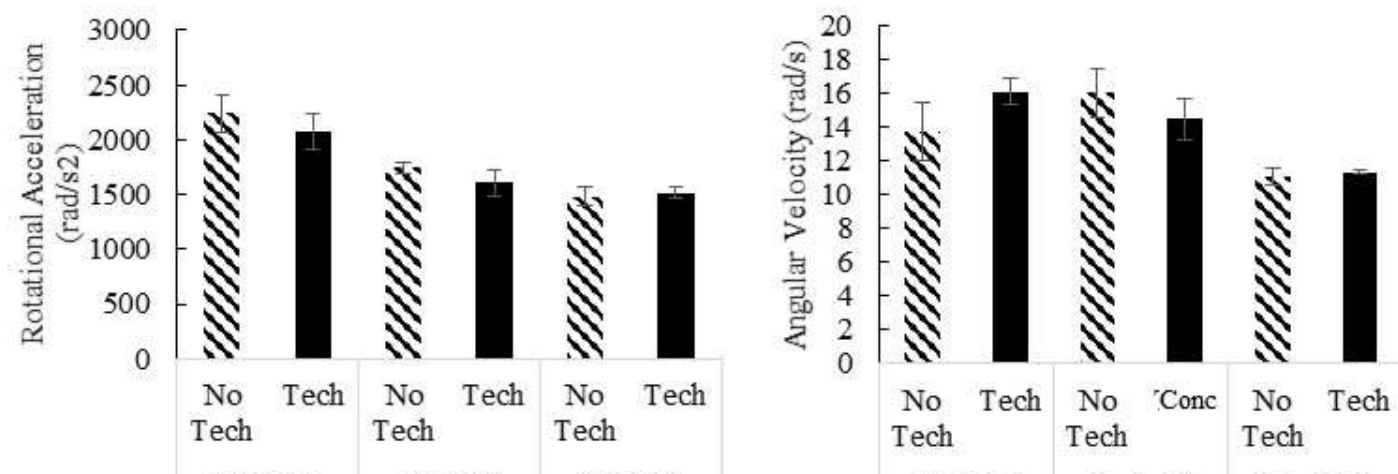

\begin{tabular}{l|l|l} 
Model 1 & Model $2 \quad$ Model 3
\end{tabular}

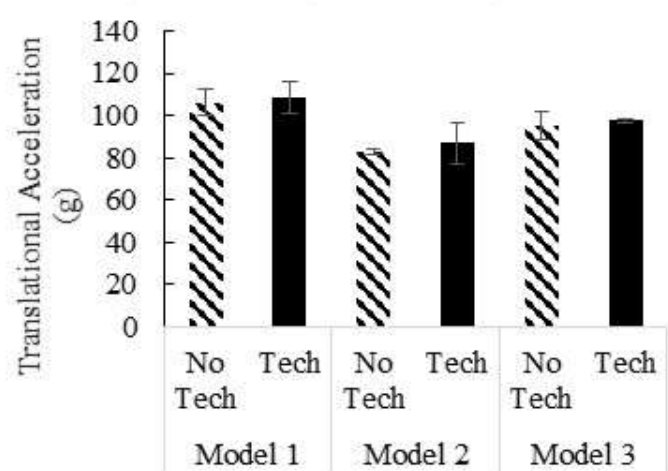

\begin{tabular}{l|l|l} 
Model 1 & Model 2 & Model 3
\end{tabular}

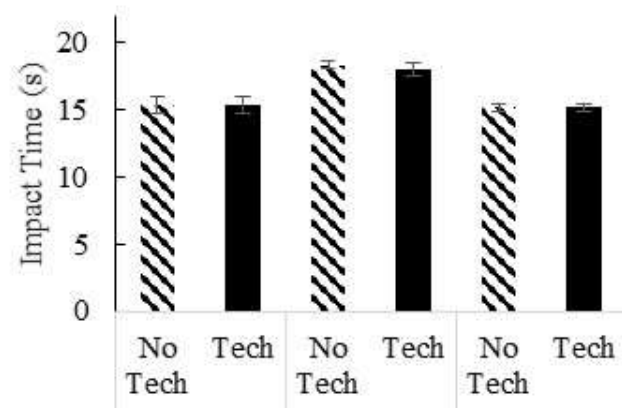

\begin{tabular}{l|l|l} 
Model 1 & Model 2 & Model 3
\end{tabular}

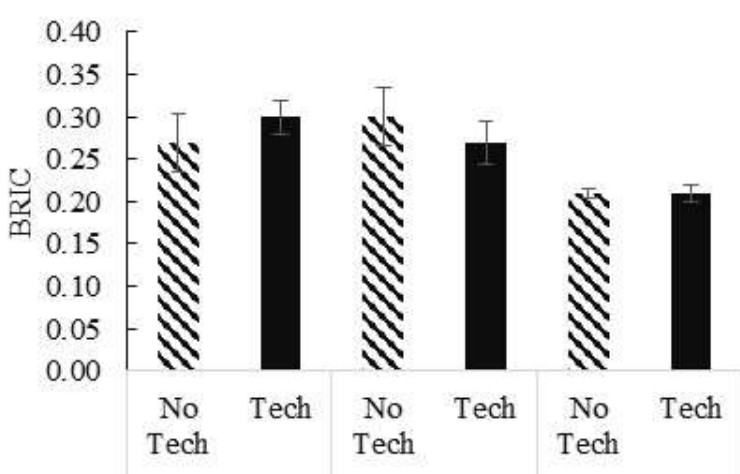

Model 1

Model 2

Model 3

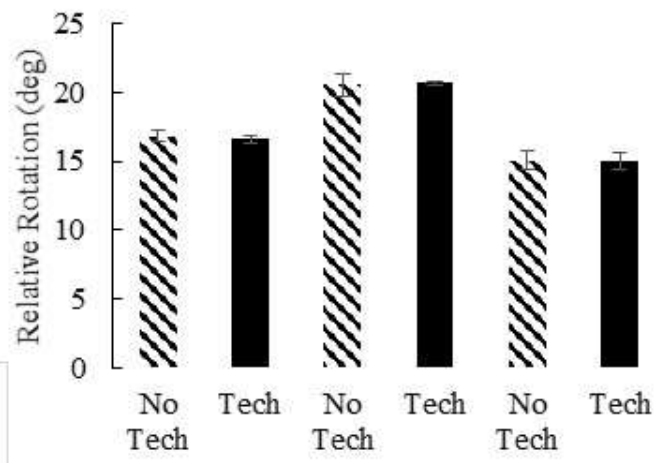

Model 1 Model 2 Model 3 
Figure A4. With average rotational acceleration of approximately $1830 \mathrm{rad} / \mathrm{s}^{2}$ for all helmets, the results are within the range of values already published (Trotta et al 2018) where scalp was also present during the experiments.

Statistical analysis showed that the presence of a technology did not affect peak linear acceleration (pvalue $=0.228$ ), rotational acceleration ( $p$-value $=0.2327$ ), angular velocity ( $p$-value $=0.1563$ ), impact duration ( $p$ value=0.6027) or BRIC ( $\mathrm{p}$-value=0.9999). Whereas, as expected, the model of the helmet itself, affects peak linear acceleration $(p-v a l u e=2.36 \mathrm{e}-05)$, rotational acceleration $(p-$ value $=2.93 \mathrm{e}-09)$, angular velocity $(\mathrm{p}$-value $=0.0002)$, impact duration (p-value=4.59e-09). and BRIC (p-value=0.0003). The repeatability between measurements (Without-Technology (WoT) and With-Technology (WT)) in terms? of normalized standard deviation is: Model_1:WoT=7.58\%, WT=7.78\%, Model_2:WoT=2.84\%,WT=7.3\%, Model_3:WoT=5.35\%, WT=3.26\%.

The trajectories of the four tracking points for all models are presented in Figure A5. For illustrative purposes, the coordinates of point A in Model_1 were also plotted as a function of time (Figure A6). The first experiment performed for the helmet configuration WoT, was taken as a reference and the maximum difference between the coordinates of this experiment and all the subsequent experiments per configuration was calculated. The maximum difference for two sets of values, $\mathrm{x}$ and $\mathrm{y}$, is given by Eq.(1)

$$
(\text { Max.Difference })_{i}=\operatorname{Max}\left(\frac{x_{r e f}-x_{j}}{x_{r e f}}\right) \quad \text { Eq. (1) }
$$

where $\mathrm{i}$ is the point of interest, $\mathrm{x}_{\mathrm{j}}$ is the value of its coordinate and $\mathrm{x}_{\mathrm{ref}}$ is the respective reference value of Experiment 1.

The values of the maximum difference (Eq.(1)) between the coordinates of each trajectory compared to the reference, indicate high similarity between the two configurations of each helmet ranging between 0.01-0.07 for xcoordinate and 0.02-0.05 for y-coordinate for the configuration WoT (Table A1 and Table A2) and between 0.010.08 for $\mathrm{x}$-coordinate and 0.02-0.08 for y-coordinate for the configurations WT (Table A3; Table A4). As a result, no significant difference is observed between the trajectories of helmets WT and WoT.

The evolution of the relative angle of rotation seems to follow a similar profile in all six experiments per model (Figure A7), reaching an average maximum of $16.8^{\circ}, 20.6^{\circ}$ and $14.9^{\circ}$ for Model_1, 2 and 3 respectively, WoT. The corresponding values WT are $16.6^{\circ}, 20.7^{\circ}$ and $14.6^{\circ}$ respectively.

\section{Discussion}

Results show good correspondence with previous studies of oblique impacts in the presence of scalp. Trotta et al (2018a), using the same testing protocol but without anti-rotational acceleration technologies, reported values of $\approx 2000 \mathrm{rad} / \mathrm{s}^{2}$, which match the average of the reference values of this study $\left(1830 \mathrm{rad} / \mathrm{s}^{2}\right)$, and a reduction of $53 \%$ for frontal impacts when scalp was used. Stigson et al (2017) using a $45^{\circ}$ anvil and speed of $6 \mathrm{~m} / \mathrm{s}$, measured a minimum value of $4200 \mathrm{rad} / \mathrm{s}^{2}$ in the presence of technologies (excluding inflatable helmets, not assessed in this study). This value is significantly higher than what was observed herein and the study of Trotta et al. 2018a, where 
the scalp is present without an integrated technology. For impacts on a $45^{\circ}$ anvil and speed of $6.2 \mathrm{~m} / \mathrm{s}$, Bliven et al (2019) reported values of $5683 \mathrm{rad} / \mathrm{s}^{2}$ when Model_3 was used and $1962 \mathrm{rad} / \mathrm{s}^{2}$ for a technology based on a honeycomb structure, which corresponded to $21 \%$ and $72 \%$ reduction from a reference value of $7243 \mathrm{rad} / \mathrm{s}^{2}$. Bottlang et. al. (2020) reported a reduction of 37\% and 22\% for helmets with Model_2 and 3 respectively at an impact speed of $6.2 \mathrm{~m} / \mathrm{s}$ (Table A5). The repeatability of the results herein are consistent with the aforementioned studies where the scalp was not included. Although direct comparisons of the absolute values should best be avoided due to differences in testing protocols, the aforementioned studies agree on the contribution of such technologies in absence of the scalp and in presence of a neckform, that is often suggested to lead to lower absolute values. Such reduction was not observed in the present study where the scalp was incorporated. It seems that factors like scalp-helmet $\mathrm{CoF}$, scalp-skull $\mathrm{CoF}$ and the material properties of the scalp, have an additional influence when anti-rotational technologies are considered. The working principle of each technology and the different interfaces are illustrated in a simplified yet condensed way in Figure 4 and Figure A9 where a small area of HIII is approximated by a small flat region.

- Interface_1: Scalp-Headform. Shearing deformation of HIII surface, is illustrated by a small shift of the layer. In addition to compression, shearing is expected due to the low but nonetheless existing $\mathrm{CoF}$ on the interface and the variable radius of the headform surface that can obstruct the scalp's movement.

- Interface_2: Scalp-Technology.

- Interface_3: Scalp-EPS. The scalp, as a deformable layer, covers the pads of the different technologies and fills the space between them and contacts the EPS. This is evident for Model_1 and 2 where the EPS is not entirely covered while the thickness of the pads is $\approx 2 \mathrm{~mm}$, significantly less than the thickness of the scalp (3-7mm).

- Interface_4: Technology-EPS. Sliding between these surfaces occurs only for Model_3 since the pads of the other two are fixed to the liner.

When the technologies are removed, only interfaces 1 and 3 are present.

The factors expected to influence the difference between helmets WT and WoT, are the freedom of motion allowed on the interfaces and the deformation of the materials used for each technology. The CoF of interfaces 1 and 3 is very low, which can allow significant sliding and reduced rotational acceleration, even when a technology is not implemented. If sliding is already significant compared to the effects induced by added technologies, their functionality could be obscured. The additional thickness provided by the scalp layer $(3-7 \mathrm{~mm})$ represents a 3.5\% increase in the distance between the $\mathrm{CoG}$ and the mid-surface of the scalp. While this would alter the MOI of the headform, it is unlikely to have a substantial influence on the results. Both configurations showed similar kinematics without statistical difference in terms of acceleration, velocity, relative rotation, impact time and severity of injury. The helmet model was found to be the only source of statistical difference. This suggests that the parameter that contributes the most to the reduction of rotational acceleration, is the CoF between headformscalp, allowing equally low values of rotational acceleration in the presence or absence of different technologies. With the overall behaviour seemingly dominated by the low CoF of the weakest layers, technologies based on material deformation or low friction, are not easily triggered. 
By visual inspection of the helmets, some possible causes for this behaviour could be identified. For low shearing resistance technologies, the interfaces at play are 1,2,3 and 4. Properties of interest are the shearing resistance of the technologies, their geometric limitations/dimensions and their interface with the scalp. The shearing resistance of the technologies should be significantly lower than the combined shearing resistance of the scalp and the low friction between the surfaces that is in contact with, for their effect to be detectable. For Model_1, the deforming pads are positioned on a limited area of the helmet, with the scalp contacting EPS over most of the helmet's surface, limiting their area of effect. The deformation of the pads was qualitatively assessed to be small $(\approx 1-2 \mathrm{~mm})$. This allows reduced displacement of the headform on the liner (Interface_3), especially if combined with the gripping effect of the pads on the scalp in areas where the scalp fills the space in between the pads. The pads of Model_2 are better distributed on the helmet's liner, covering about 30\% of its frontal and top area but the scalp can still contact EPS between the pads. The deformation of the pads was measured to be slightly larger than Model_1 $(\approx 2 \mathrm{~mm})$. The working principle of Model_3 is based 1) on a low friction layer covering the entire liner and 2) the deformable strings that hold the mechanism in place. The distance that this layer can slide on the liner was measured to be $\approx 10-15 \mathrm{~mm}$. The focus here is on interfaces 1,2 and 4 . Important variables in this case are the CoF of Interface_4 and the Elastic Modulus of the strings that defines their ability to stretch to allow sliding. If these variables are not low enough, then the low friction of Interface 1 will have a dominant role and the contribution of a low friction layer will be reduced. A possible limitation to this study, is that the CoF of the duct tape-helmet interface is yet to be determined. While lower than that of the rubber surface of HIII arguably making this approach more realistic than placing the scalp directly on the headform, friction experiments could be designed to further investigate how it compares against the CoF of 0.06 defined between skull-scalp. The internal metal skeleton of HIII was preserved but the vinyl layer of HIII is considered more compliant than human skull. Future headforms should consider the overall compliance of the headform. Furthermore, taking into account studies that suggest that the presence of a neckform can drastically affect the forces applied on the head, a topic worth investigating would be the combined effect of an integrated neckform and a biofidelic scalp along with possible ways to accurately assess the displacement of the headform on the liner's surface. Finally, testing on additional axes could further corroborate the results of the study.

\section{Acknowledgements}

This work was supported by the European Union's Horizon 2020 research programme under the Marie Sklodowska-Curie grant agreement No. 642662.

\section{References}

Bland, M.L., McNally, C., Rowson, S.,Differences in Impact Performance of Bicycle Helmets During Oblique Impacts. J. Biomech. Eng. 2018; 140(9). https://doi.org/10.1115/1.4040019

Bland, M.L., McNally, C., Rowson, S., Development of the STAR Evaluation System for Assessing Bicycle Helmet Protective Performance Annals of Biomedical Engineering volume 2019; 48, 47-57 https://doi.org/10.1007/s10439-019-02330-0 
Bland M. L., McNally C, Rowson S. Headform and Neck Effects on Dynamic Response in Bicycle Helmet Oblique Impact Testing. Proceedings of IRCOBI Conference September 12-14, 2018; Athens, Greece

Bliven E, Deck C, Madey S, Bourdet N Evaluation of a novel bicycle helmet concept in oblique impact testing. Accident Analysis \& Prevention 2019; 124:58-65 https://doi.org/10.1016/j.aap.2018.12.017

Bottlang M., Rouhier A., Tsai S., Gregoire J, Madey S Impact Performance Comparison of Advanced Bicycle Helmets with Dedicated Rotation-Damping Systems Annals of Biomedical Engineering, 2020; 48(1) 68-78 https://doi.org/10.1007/s10439-019-02328-8

Bourdet, N., Deck, C., Serre, T., Perrin, C., Llari, M., Willinger, R., In-depth realworld bicycle accident reconstruction. Int. J. Crashworthiness. 2014; 19 (3), 222-232. https://doi.org/10.1080/13588265.2013.805293

Bowling J., Botting J., Porcine Sebaceous Cyst Model: An Inexpensve, Reproducible Skin Surgery Simulator Dermatologiv Surgery 2006; 31(8) 953-956 https://doi.org/10.1111/j.1524-4725.2005.31811 of joint international conference MPTL 16 September 15-17. 2011; Ljubljana, Slovenia

Connor T. Stewart M. Burek R. Gilchrist D. M. Influence of headform mass and inertia on the response to oblique $\begin{array}{llllll}\text { impacts International } & \text { Journal } & \text { of } & \text { Crashworthiness } & \text { 2019; }\end{array}$ https://doi.org/10.1080/13588265.2018.1525859

Deck C., Bourdet N., Meyer F., Protection performance of bicycle helmets, Journal of Safety Research 2019; 71: 67-77 https://doi.org/10.1016/j.jsr.2019.09.003

Ebrahimi I, Golnaraghi F, Wang G. G. Factors influencing the oblique impact test of motorcycle helmets. Traffic injury prevention. 2015; 16:404-8. https://doi.org/10.1080/15389588.2014.937804

Ge, L Huang Z., Wei H: Skin Graft Preservation, Skin Grafts - Indications, Applications and Current Research Intech $2011 ; 159-174$ 10.5772/23084

Kendall M, Walsh E.S, Hoshizaki T.B. Comparison between Hybrid III and Hodgson-WSU headforms by linear and angular dynamic impact response. J Sports Eng Technol. 2012; 226(3-4):260-265. https://doi.org/10.1177/1754337112436901

Klug C., Feist F., Tomasch |E. Testing of bicycle helmets for preadolescents IRCOBI Conference Proceedings 911 September 2015; Lyon, France

McIntosh A, Dowdell B, Svensson N. Pedal cycle helmet effectiveness: a field study of pedal cycle accidents. Accident Analysis \& Prevention. 1998; 30:161-8. https://doi.org/10.1016/s0001-4575(97)00089-4

Pramudita J, Shimizu Y, Tanabe Y, Masato I, Watanabe R. Tensile Properties of Porcine Skin in Dorsal and Ventral Regions. Journal of the Japanese Society for Experimental Mechanics 2014; (14)245-250. https://doi.org/10.11395/jjsem.14.s245

Rowson, B., Rowson, S., Duma, S.M., Hockey STAR: a methodology for assessing the biomechanical performance of hockey helmets. Annals of Biomechanical Engineering 2015; 43 (10):2429-2443. https://doi.org/10.1007/s10439-015-1278-7

Sahoo D., Deck, C., Willinger, R., Brain injury tolerance limit based on computation of axonal strain. Accident. Analysis and. Prevention. 2016; 92:53-70. https://doi.org/10.1016/j.aap.2016.03.013

Seery G. E. Surgical anatomy of the scalp. Dermatologic surgery. 2002; 28:581-7. https://doi.org/10.5005/jp/books/12881_19 
Stigson H., Rizzi M., Ydenius A., Engström E., Anders Kullgren A. Consumer Testing of Bicycle Helmets IRCOBI Conference Proceedings 2017

Tolhurst D.E, Carstens M.H, Greco R.J, Hurwitz D.J. The surgical anatomy of the scalp. Plastic and reconstructive surgery. 1991; 87:603-12. https://doi.org/10.1097/00006534-199208000-00036

Trotta A, Zouzias D, Bruyne D G, Annaidh N A, The importance of the Scalp in head impact kinematics Annals of Biomedical Engineering 2018a; 46(6) 1-10 https://doi.org/10.1007/s10439-018-2003-0

Trotta A, Annaidh N, Burek R, Pelgrims B, Ivens J. Evaluation of the head-helmet sliding properties in an impact test. Journal of Biomechanics 2018b; 75:28-34 https://doi.org/10.1016/j.jbiomech.2018.05.003

Trotta, A., Annaidh, Aisling.Ní. Mechanical characterisation of human and porcine scalp tissue at dynamic strain rates, Journal of the Mechanical Behavior of Biomedical Materials, 2019; 100 https://doi.org/10.1016/j.jmbbm.2019.103381

Zouzias D, Bruyne G. D, Ivens J A proposed motion tracking technique to assess the kinematics of oblique impacts

\section{Figures}

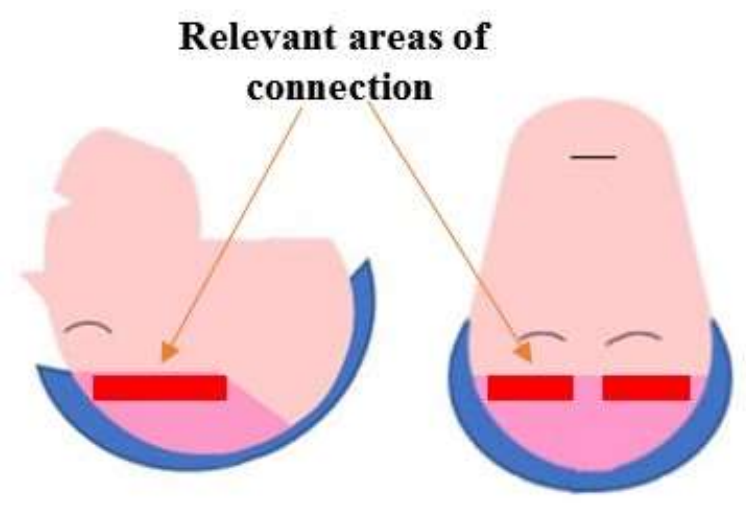

Figure 1: Scalp arrangement on the headform (Figure adapted from Trotta et al. 2018a) (Picture of the set-up in Appendix Figure A8) 

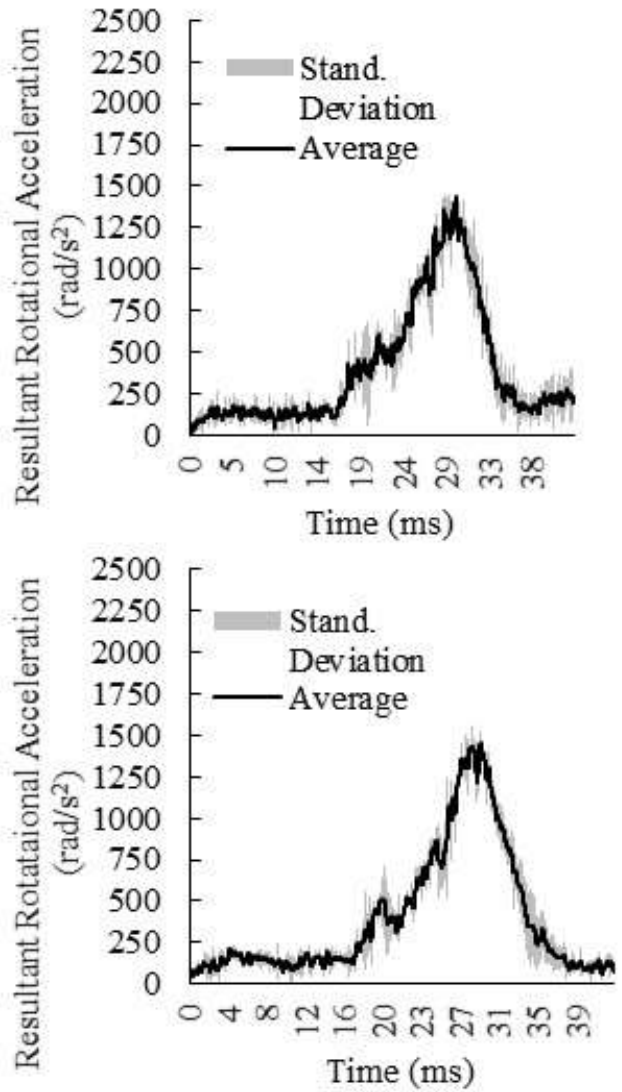

Figure 2: Resultant rotational acceleration for Approach_1 (Model_3). Continuous black line: Average value of rotational acceleration. Shaded line: Standard deviation. Top: Without Technology, Bottom: With Technology (Models_1 and 2 of Approach_2 in Appendix Figure A3)

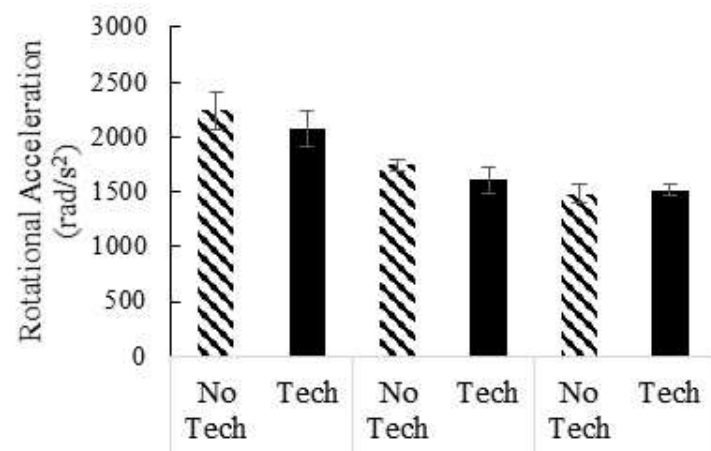

Model $1 \quad$ Model $2 \quad$ Model 3

7 Figure 3: Mean rotational acceleration per model. The error bars identify standard deviation (Additional charts in Appendix 

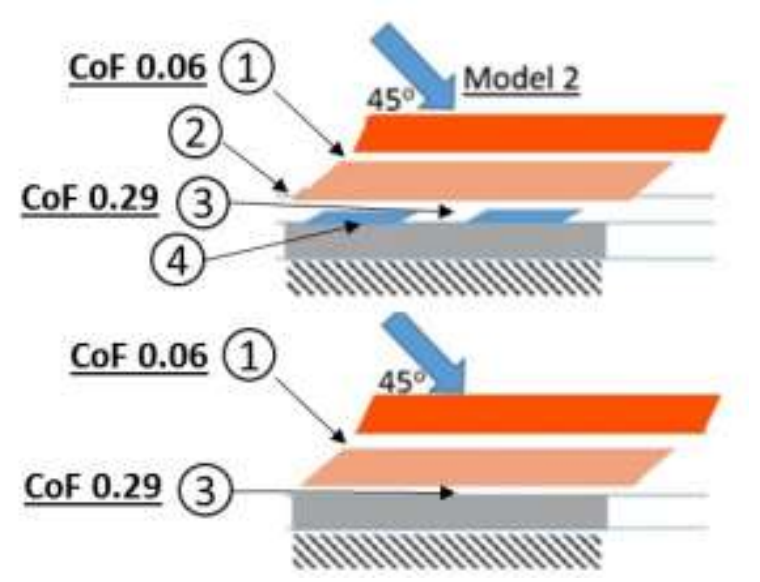

1 Figure 4: Schematics of working principle of POC Spin and corresponding CoF for surface 1 and 3 (Trotta A. 2018). Upper row:

3 Technologies are included. Lower row: Technologies are not included. Interface_1: Headform-Scalp, Interface_2: Scalp -

4 Technology, Interface_3: Scalp-EPS, Interface_4: Technology-EPS. An arrow is used to illustrate the 450 direction of the

impact, relatively to the anvil. The other two technologies are illustrated in Appendix Figure A9 


\section{APPENDIX}

\section{Conclusions}

In conclusion, technologies aiming to reduce rotational acceleration, have managed to successfully do so, for the current generation of dummy-heads (Bliven et al. 2019). However, dummies and helmet technologies should evolve in order to grasp the complexity of injury mechanisms. More specifically the main points of this study are:

- Three technologies against rotational acceleration were assessed in combination with a modified headform.

While two of these technologies have been proven effective on an ordinary HIII, they showed no statistical
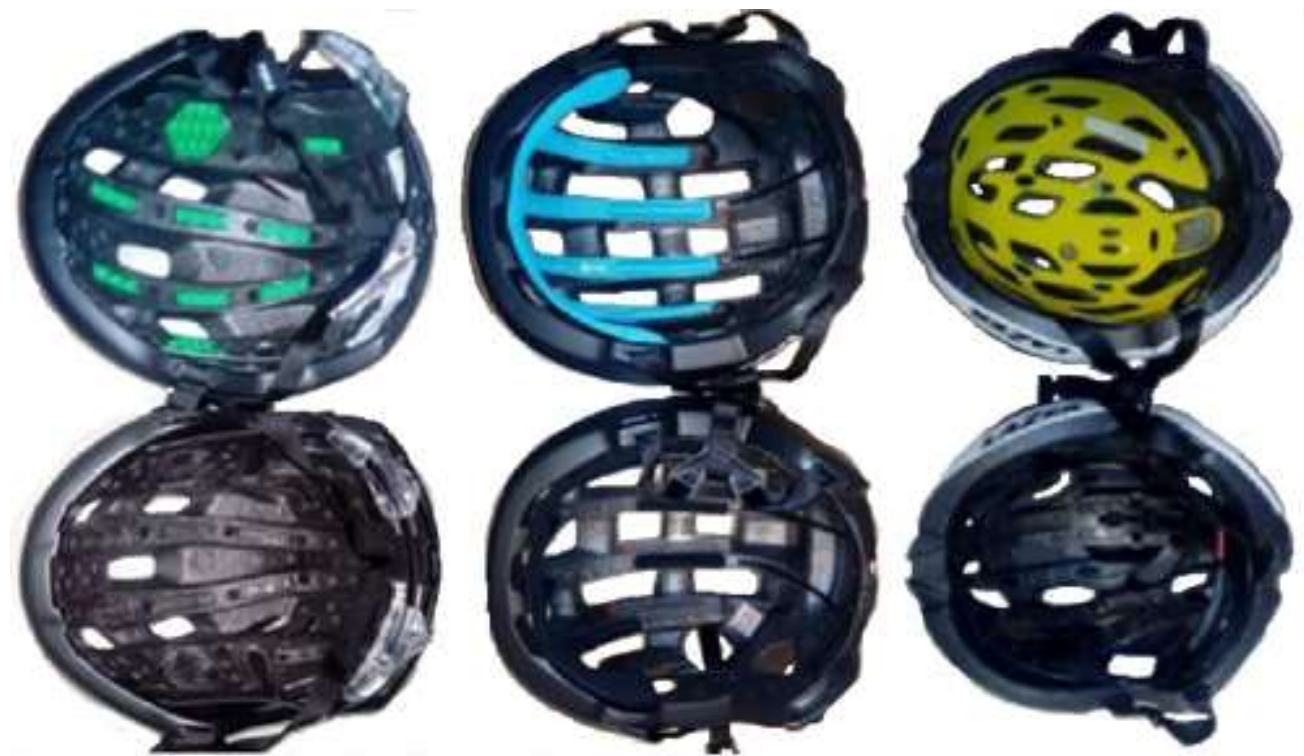

Figure A1: Helmets tested. On the top row the version of the helmet with the technology is presented. On the bottom row is the version with the technology removed or not installed. From left to right Model_1-LDL, Model_2-Spin, Model_3-MIPS 


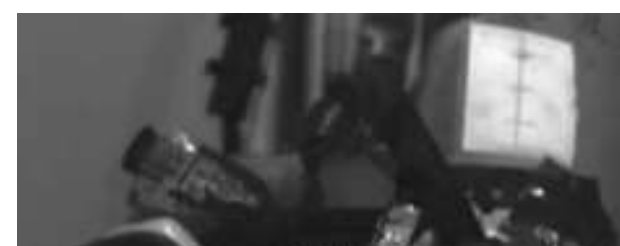

$-$

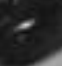
EY

1
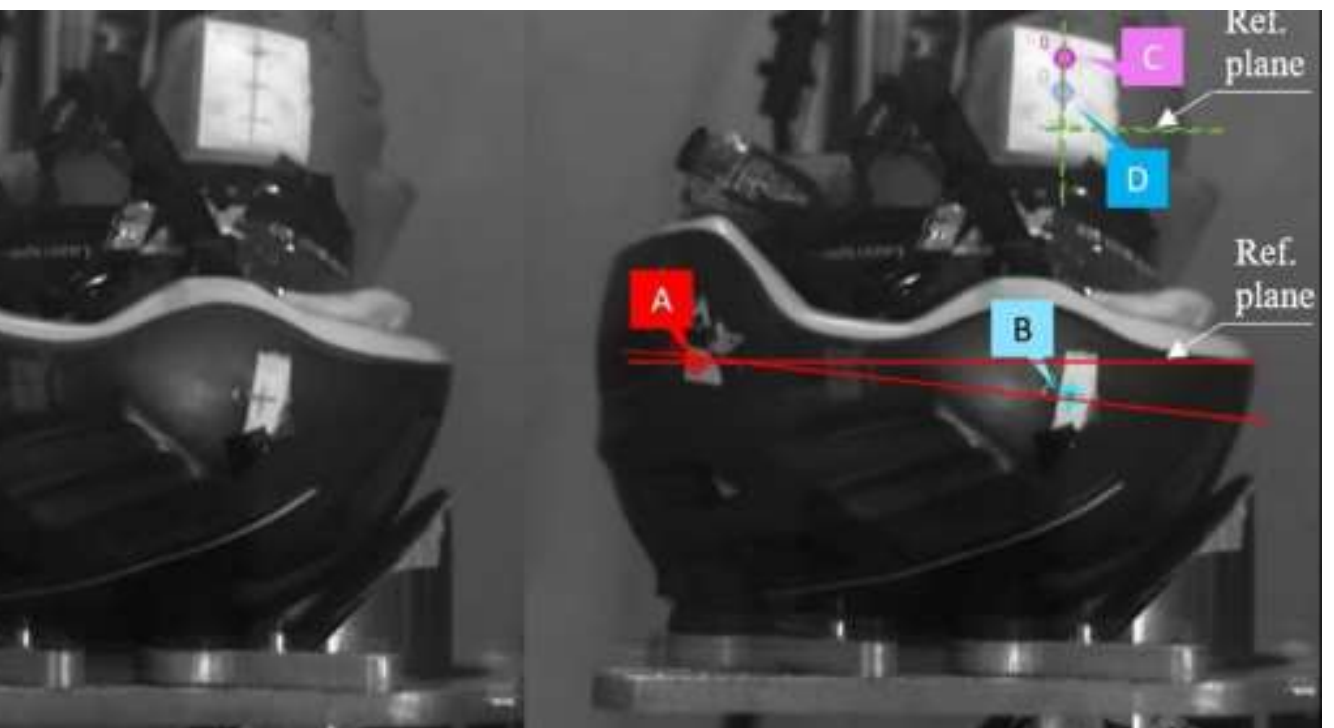

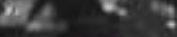

Ref.

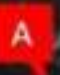

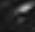

plane

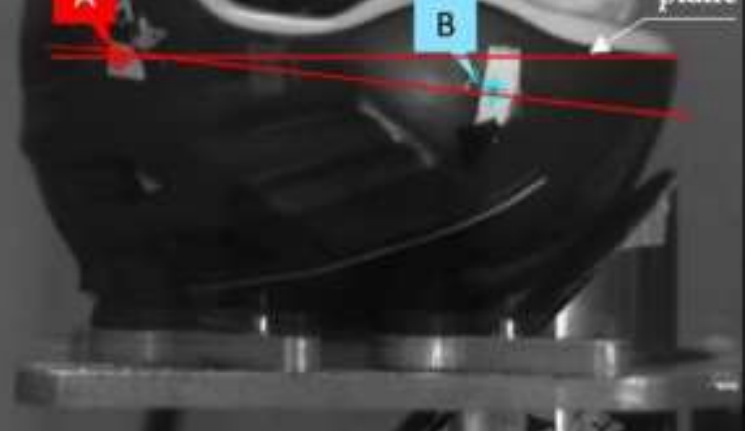

Figure A2: Illustration of tracking points marked on headform and helmet (Left) and their representation within the environment of the tracking software (Right) $A$ and B: Points on the helmet. C and D: Points on headform. Horizontal lines:

Reference planes from which angle of rotation is being measured. Inclined lines: Lines defined by the tracking points to measure the rotation of the headform and the helmet (Zouzias et al 2017). The pair of red lines corresponds to the helmet. The pair of green lines corresponds to the headform 

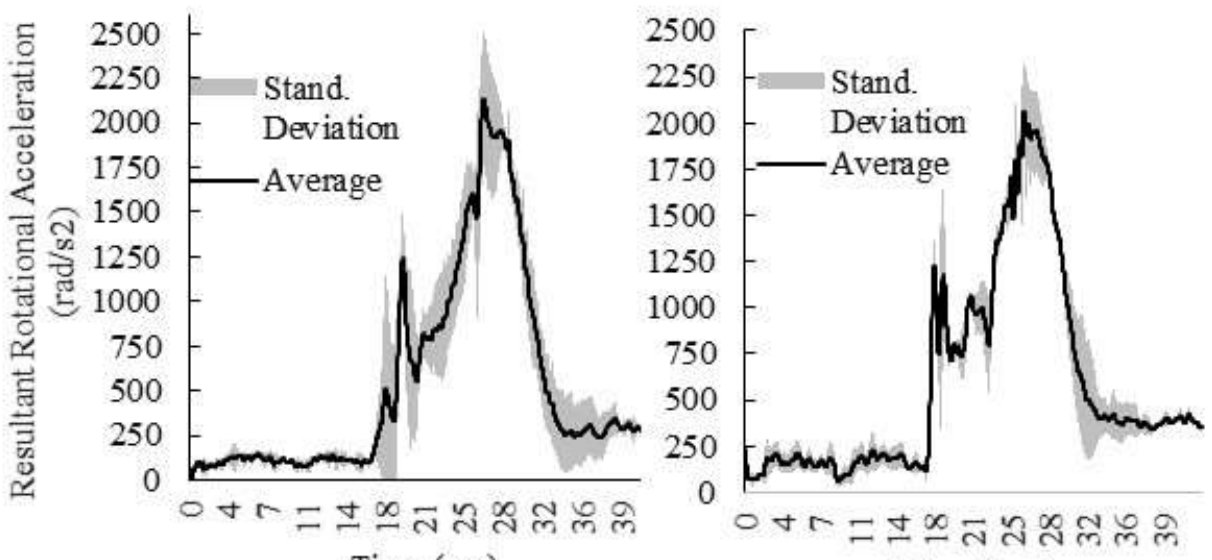

Time (ms)

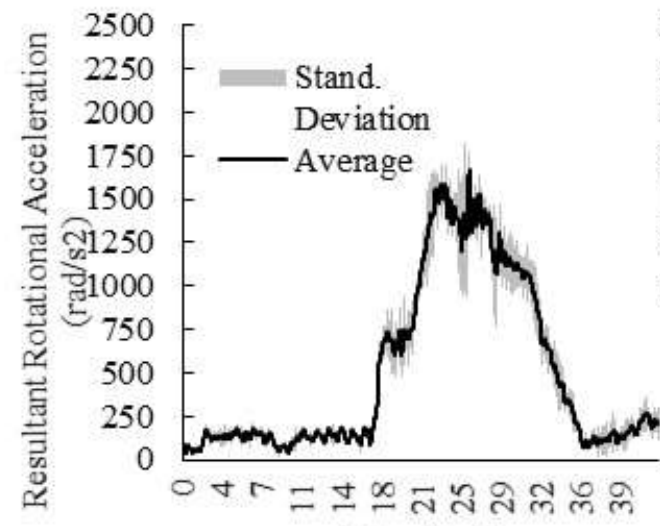

Time (ms)

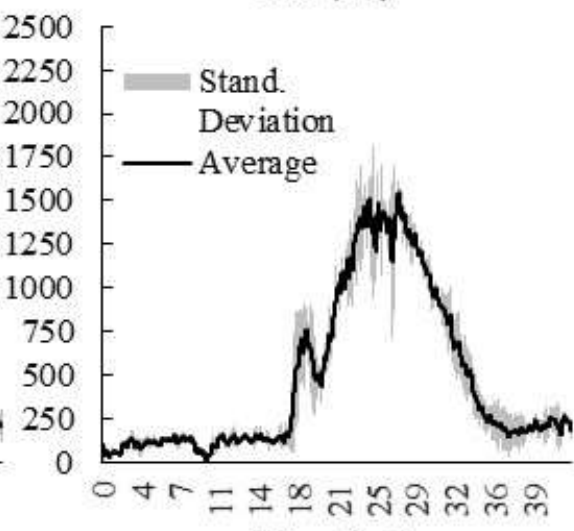

Time (ms)
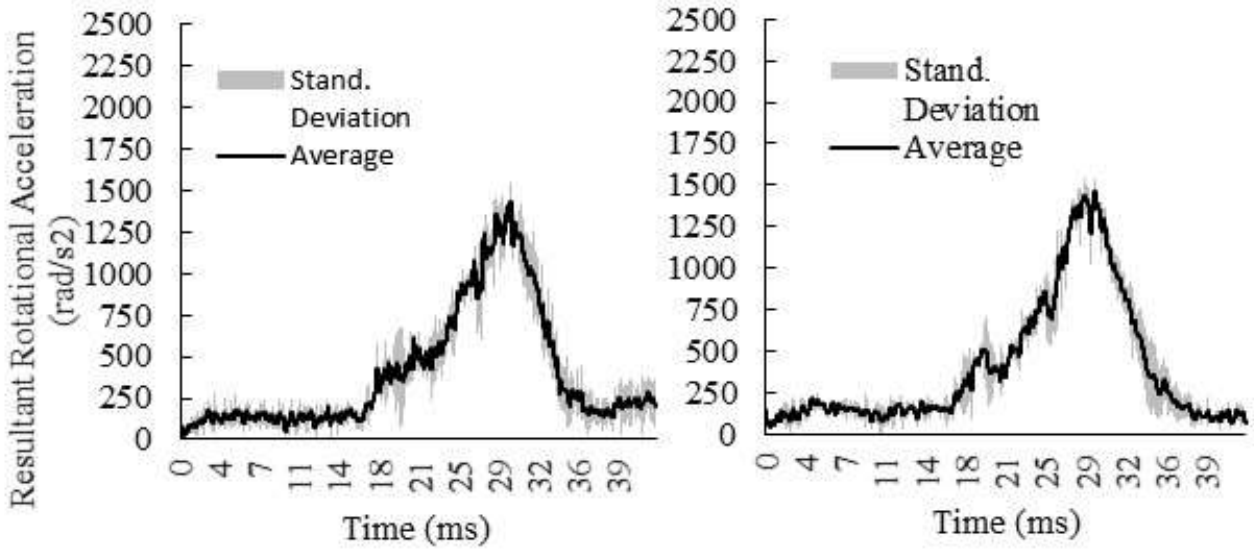

Figure A3: Resultant rotational acceleration resulting from the oblique impact. Continuous black line: Average value of rotational acceleration for helmets with and without anti-rotational acceleration technology installed. Shaded line: Standard deviation.Top row: Model_1, Middle: Model_2, Low: Model_3. Left Column: Without Technology, Right Column With Technology 

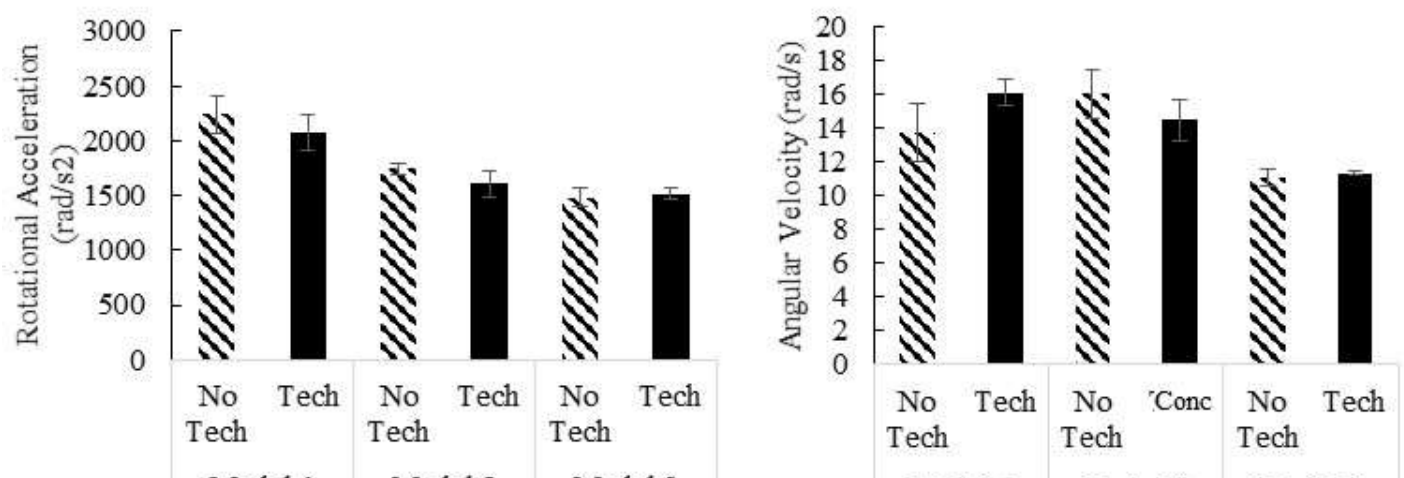

\begin{tabular}{l|l|l|l} 
Model 1 & Model 2 & Model 3
\end{tabular}
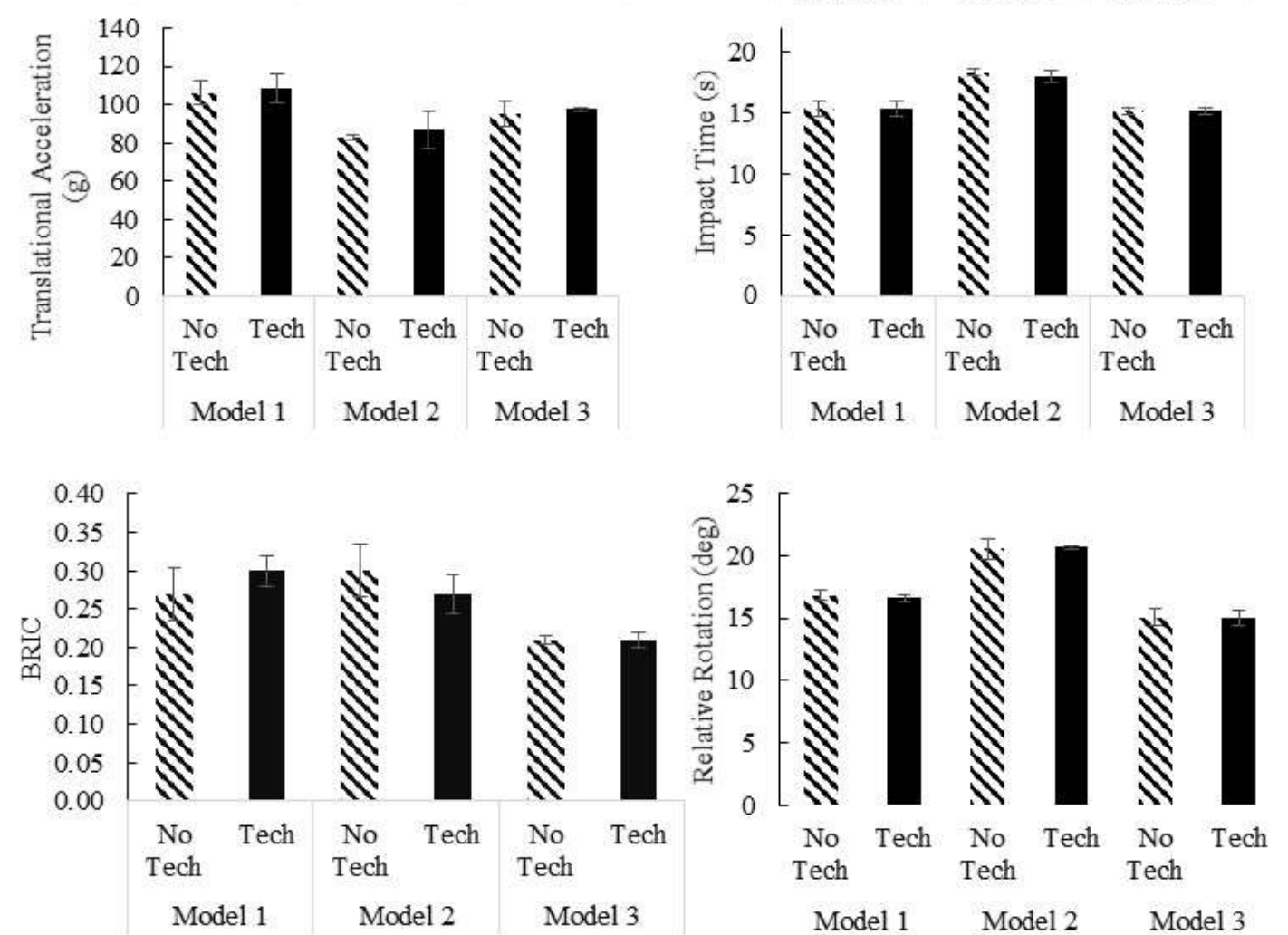

Figure A4: Bar chart showing the mean results of the oblique impacts in terms of linear acceleration, rotational acceleration, angular velocity and impact time. The error bars identify standard deviation

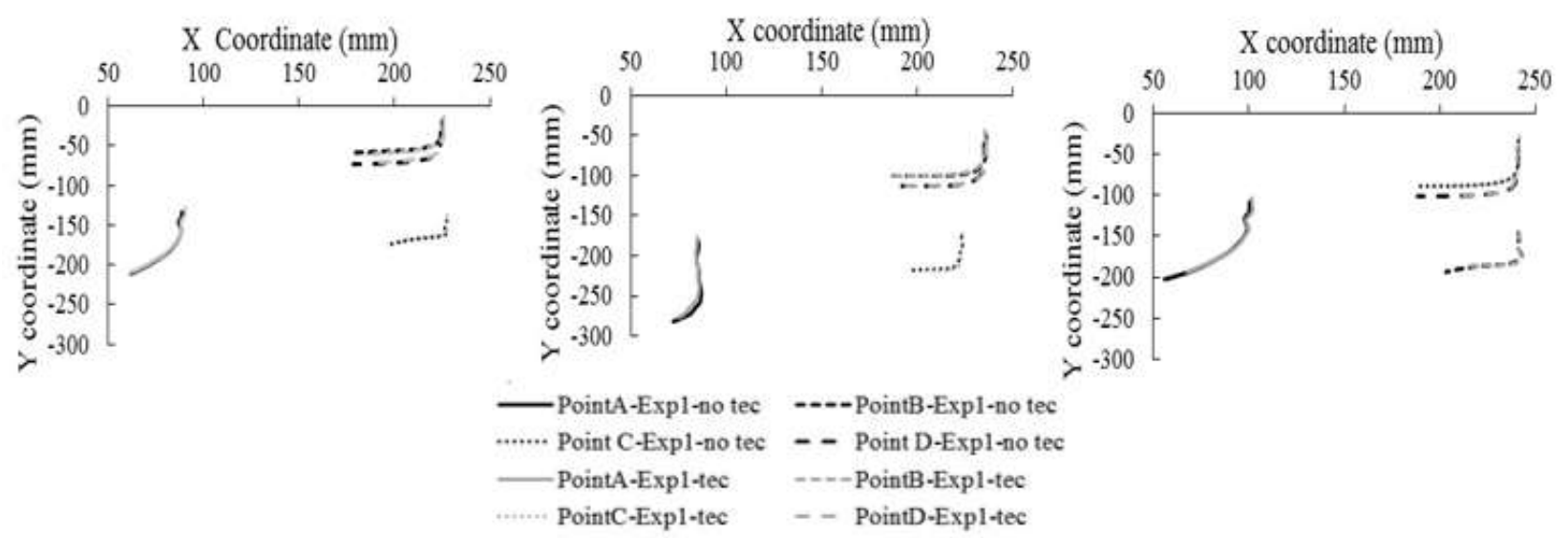



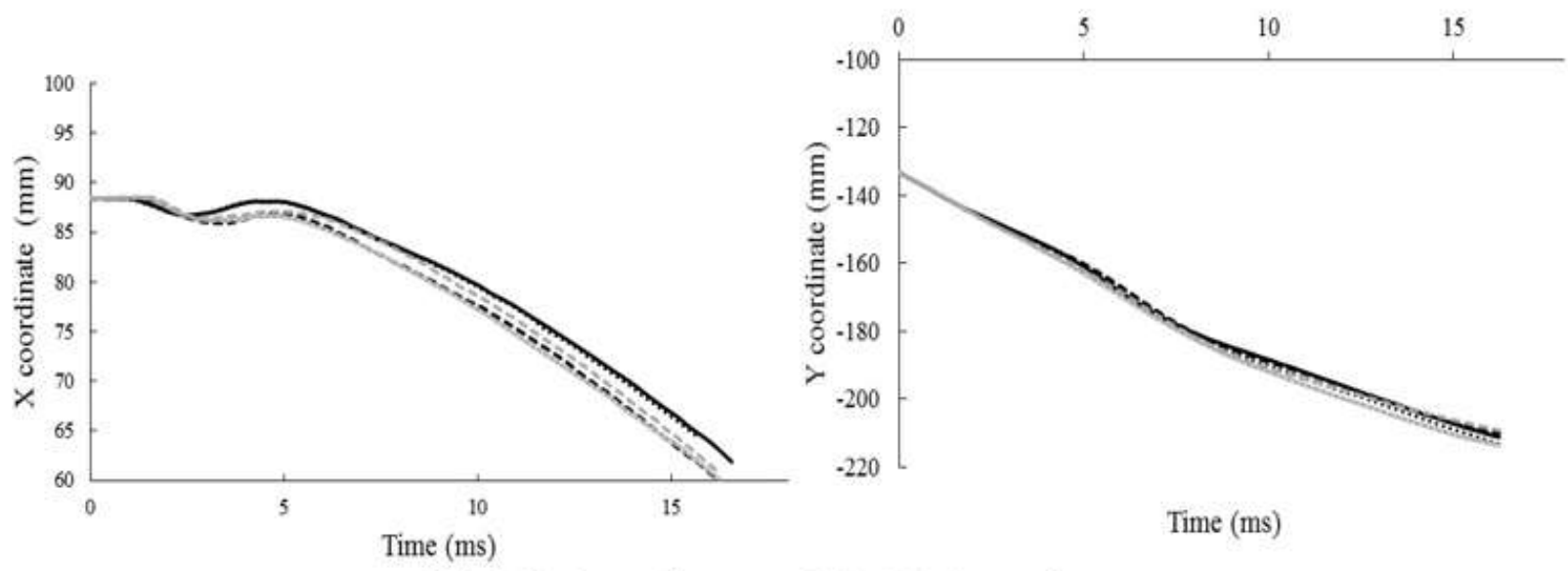

Time (ms)
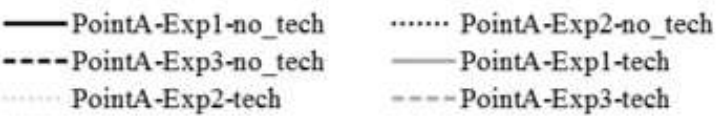

Figure A6: Comparison of coordinates of tracking point A as a function of time for Model_1. Left: $x$ coordinate, Right: $y$ coordinate
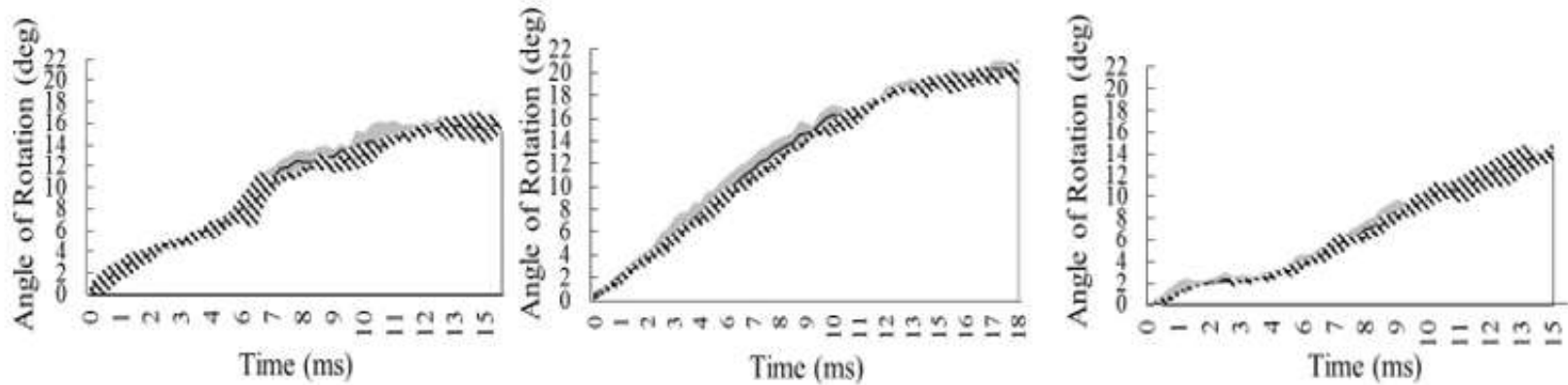

- Stand. Deviation-Tech $\square$ Tech

.w:Stand. Deviation-no tech -... No tech

Figure A7: Relative rotation (degrees) between headform and helmet during impact. Left: Model_1, Middle: Model_2, Right: Model_3 

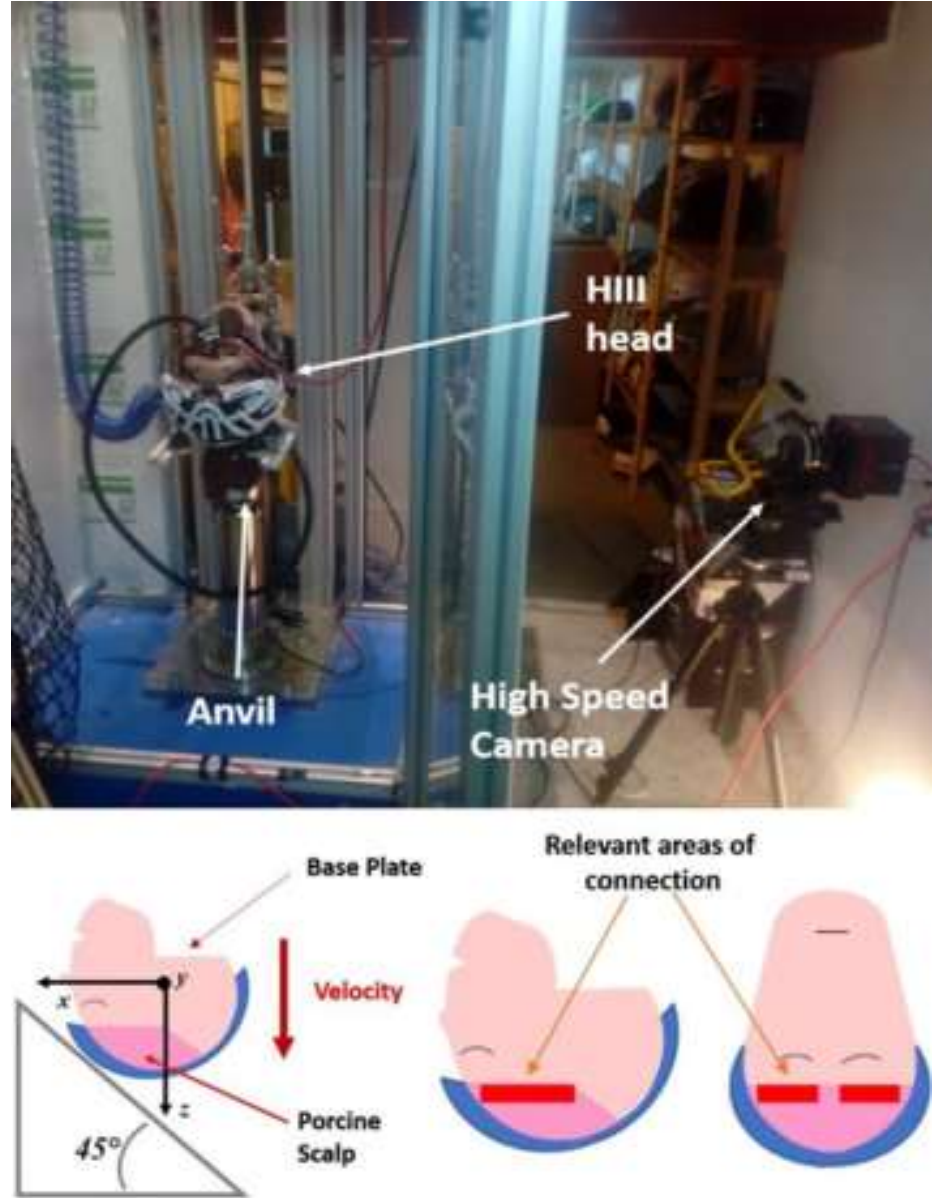

Figure A8: Experimental set-up and scalp arrangement on the headform (Figure adapted from Trotta et al. $2018 \mathrm{a}$
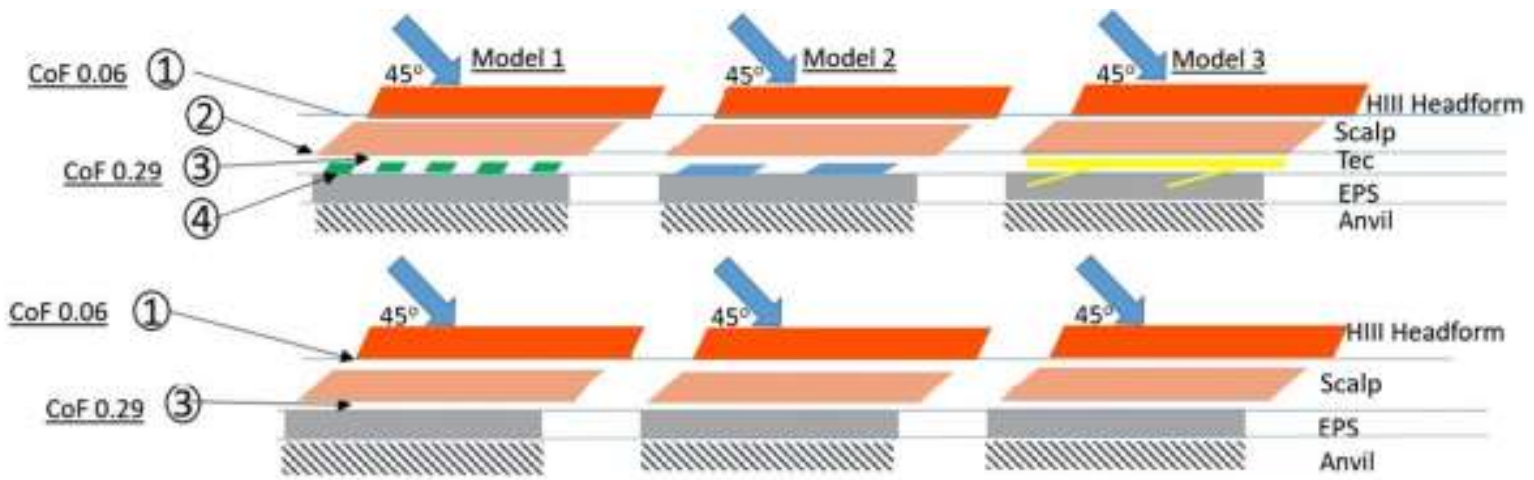

Figure A9: Schematics of working principle of each technology and corresponding CoF for surface 1 and 3 (Trotta A. 2018). From left to right: LDL, Spin, MIPS. Upper row: Technologies are also included. Lower row: Technologies are not included. Interface_1: Headform-Scalp, Interface_2: Scalp -Technology, Interface_3: Scalp -EPS, Interface_4: Technology -EPS. An arrow is used to illustrate the $45^{\circ}$ direction of the impact, relatively to the anvil

Table A1: Average maximum difference for the X coordinate of each tracking point per model for the three trials without tech

\begin{tabular}{|c|c|c|c|c|c|c|c|c|c|c|c|c|}
\hline $\begin{array}{l}\text { For the three trials } \\
\text { without tech }\end{array}$ & \multicolumn{4}{|c|}{ Model_1 } & \multicolumn{4}{|c|}{ Model_2 } & \multicolumn{4}{|c|}{ Model_3 } \\
\hline Point & $\mathbf{A}$ & B & $\mathbf{C}$ & D & $\mathbf{A}$ & B & C & D & $\mathbf{A}$ & B & C & D \\
\hline Average Max Diff. & 0,03 & 0,01 & 0,01 & 0,01 & 0,02 & 0,01 & 0,01 & 0,01 & 0,07 & 0,03 & 0,01 & 0,01 \\
\hline $\begin{array}{l}\text { Standard } \\
\text { Deviation }\end{array}$ & 0,02 & 0,01 & 0,01 & 0,01 & 0,01 & 0,01 & 0,01 & 0,01 & 0,05 & 0,02 & 0,02 & 0,02 \\
\hline
\end{tabular}


Table A2: Average maximum difference for the Y coordinate of each tracking point per model for the three trials without tech

\begin{tabular}{|l|c|c|c|c|c|c|c|c|c|c|c|c|}
\cline { 2 - 13 } For the three trials without tech & \multicolumn{4}{|c|}{ Model_1 } & \multicolumn{4}{c|}{ Model_2 } & \multicolumn{4}{c|}{ Model_3 } \\
\hline Point & A & B & C & D & A & B & C & D & A & B & C & D \\
\hline Average Max Diff. & 0,02 & 0,02 & 0,05 & 0,06 & 0,02 & 0,02 & 0,05 & 0,04 & 0,03 & 0,02 & 0,05 & 0,05 \\
\hline Standard Deviation & 0,02 & 0,01 & 0,04 & 0,06 & 0,02 & 0,01 & 0,05 & 0,04 & 0,02 & 0,01 & 0,06 & 0,05 \\
\hline
\end{tabular}

Table A3:: Average maximum difference for the X coordinate of each tracking point per model for the three trials with tech in

\begin{tabular}{|c|c|c|c|c|c|c|c|c|c|c|c|c|}
\hline \multirow{3}{*}{$\begin{array}{l}\text { For the three trials without tech } \\
\text { Point }\end{array}$} & \multirow{2}{*}{\multicolumn{4}{|c|}{ Model_1 }} & \multirow{2}{*}{\multicolumn{4}{|c|}{ Model_2 }} & \multirow{2}{*}{\multicolumn{4}{|c|}{ Model_3 }} \\
\hline & & & & & & & & & & & & \\
\hline & $\mathbf{A}$ & B & $\mathbf{C}$ & D & $\mathbf{A}$ & B & $\mathrm{C}$ & D & $\mathbf{A}$ & B & $\mathbf{C}$ & D \\
\hline Average Max Diff. & 0,01 & 0,01 & 0,01 & 0,01 & 0,08 & 0,03 & 0,02 & 0,03 & 0,05 & 0,02 & 0,01 & 0,01 \\
\hline Standard Deviation & 0,00 & 0,01 & 0,01 & 0,01 & 0,05 & 0,02 & 0,01 & 0,01 & 0,01 & 0,01 & 0,01 & 0,01 \\
\hline
\end{tabular}

Table A4: Average maximum difference for the Y coordinate of each tracking point per model for the three trials with tech in

\begin{tabular}{|c|c|c|c|c|c|c|c|c|c|c|c|c|}
\hline \multirow{2}{*}{$\begin{array}{l}\text { For the three trials without tech } \\
\text { Point }\end{array}$} & \multicolumn{4}{|c|}{ Model_1 } & \multicolumn{4}{|c|}{ Model_2 } & \multicolumn{4}{|c|}{ Model_3 } \\
\hline & $\mathbf{A}$ & B & $\mathbf{C}$ & D & $\mathbf{A}$ & B & $\mathbf{C}$ & D & $\mathbf{A}$ & B & $\mathbf{C}$ & D \\
\hline Average Max Diff. & 0,02 & 0,02 & 0,08 & 0,06 & 0,02 & 0,02 & 0,07 & 0,08 & 0,04 & 0,02 & 0,08 & 0,08 \\
\hline Standard Deviation & 0,01 & 0,01 & 0,03 & 0,05 & 0,01 & 0,01 & 0,06 & 0,05 & 0,01 & 0,01 & 0,04 & 0,04 \\
\hline
\end{tabular}

Table A5: Overview of results reported in literature on rotational acceleration

\begin{tabular}{|c|c|c|c|c|}
\hline & $\frac{\text { Trotta A. et al }}{\frac{2018^{\circ}}{\text { (scalp-no }}}$ & $\frac{\text { Bliven E. et al } 2019}{\underline{(\text { no scalp })}}$ & $\begin{array}{l}\text { Bottlang et. al } 2020 \\
\text { (no scalp) }\end{array}$ & $\begin{array}{l}\text { Current } \\
\text { study } \\
\text { (Scalp) }\end{array}$ \\
\hline $\begin{array}{l}\text { Rot Acc-No } \\
\text { Scalp/Stockings- } \\
\left.\text { No Tech.(r/s }{ }^{2}\right) \\
\end{array}$ & $\approx 4400$ & 7243 & $\approx 7400$ & - \\
\hline $\begin{array}{l}\text { Rot Acc-No } \\
\text { Scalp/Stockings- } \\
\text { With Tech. }\left(r / s^{2}\right)\end{array}$ & - & $\begin{array}{c}\text { Model_3: } 5683(-21 \%) \\
\text { HoneyComb: } 1962(-72 \%)\end{array}$ & $\begin{array}{c}\text { Model_3: } \approx 5770(-22 \%) \\
\text { Model_2: } \approx 4660(-37 \%) \\
\text { Model_1: } \approx 11900 \\
(+61 \%)\end{array}$ & - \\
\hline $\begin{array}{l}\text { Rot Acc With } \\
\text { Scalp/Stockings- } \\
\text { No Tech. }\left(\mathrm{r} / \mathrm{s}^{2}\right) \\
\end{array}$ & $\approx 2000(-53 \%)$ & - & & 1830 \\
\hline $\begin{array}{l}\text { Rot Acc With } \\
\text { Scalp/Stockings- } \\
\text { With Tech. }\left(r / s^{2}\right)\end{array}$ & - & - & & $1780(\approx 3 \%)$ \\
\hline
\end{tabular}

\section{Bibliography}

Aare M, Halldin P. A new laboratory rig for evaluating helmets subject to oblique impacts. Traffic injury prevention. 2003; (3),240-8.. https://doi.org/10.1080/15389580309879

Beckwith G J, Greenwald M. R., Chu J. J., Measuring Head Kinematics in Football: Correlation Between the Head Impact Telemetry System and Hybrid III Headform Annals of Biomedical Engineering 2012; 40: 237-248 https://doi.org/10.1007/s10439-011-0422-2 
Fahlstedt M., Halldin, P., Kleiven, S., Importance of the bicycle helmet design and material for the outcome in bicycle accidents. Proceeding of International Cycling Safety Conference. November 18-19, 2014 Gothenburg, Sweden

Kleiven S. Why most traumatic brain injuries are not caused by linear acceleration but skull fractures are. Frontiers in bioengineering and biotechnology. 2013; 1 . https://doi.org/10.3389/fbioe.2013.00015

Kuo C., Fanton, M., Wu L., \& Camarillo D. Spinal constraint modulates head instantaneous center of rotation and dictates head angular motion. Journal of Biomechanics, 2018; 76:220-228. https://doi.org/10.1016/j.jbiomech.2018.05.024

Halldin P, Kleiven S. The development of next generation test standards for helmets. Proceedings of the 1st International Conference on Helmet Performance and Design. Februrary 15, 2013; London, UK

Hansen, K., Dau, N., Feist, F. Angular impact mitigation system for bicycle helmets to reduce head acceleration and risk of traumatic brain injury. Accid. Anal. Prev. 2013; 59:109-117. https://doi.org/10.1016/j.aap.2013.05.019

Mills, N.J., Gilchrist, A., Oblique impact testing of bicycle helmets. International Journal of Impact Engineering 2008; 35(9):1075-1086. https://doi.org/10.1016/j.ijimpeng.2007.05.005

Sun J, Li Z, Pan S, Feng H, Shao Y, Liu N, Huang P, Zou D, Chen Y Identification of pre-impact conditions of a cyclist involved in a vehicle-bicycle accident using an optimized MADYMO reconstruction combined with motion capture Journal of Forensic and Legal Medicine 2018; 55:9-107 